DOI: $10.7819 /$ rbgn.v16i51.1422

Área Temática: Estratégia e Comportamento Organizacional

\title{
O Empreendedor Líder e a Disseminação da Orientação Empreendedora
}

\author{
Entrepreneurial Leaders and the Dissemination of Entrepreneurial Orientation \\ El emprendedor líder y la difusión de la orientación emprendedora
}

\author{
Joáo Carlos Barreto ${ }^{1}$ \\ Vânia Maria Jorge Nassif ${ }^{2}$
}

Recebido em 12 de setembro de 2012 / Aprovado em 9 de junho de 2014

Editor Responsável: João Maurício Gama Boaventura, Dr.

Processo de avaliação: Double Blind Review

\section{RESUMO}

Esta pesquisa tem por objetivo analisar se o comportamento de liderança do empreendedor de micro e pequenas empresas, prestadoras de serviços, contribuem na disseminação das dimensôes da orientação empreendedora. Trata-se de uma pesquisa qualitativa básica de natureza exploratória e interpretativa, realizada por meio de entrevistas com um roteiro semiestruturado com cinco empreendedores líderes de MPEs. Os dados da pesquisa foram analisados por meio da análise de conteúdo proposta por Bardin (2008) e as narrativas conforme Gibbs (2009). Os resultados demonstram que os empreendedores fazem uso das dimensóes da orientaçáo empreendedora em intensidades diferentes e de maneira informal por não estarem familiarizados com a prática das dimensôes da orientação empreendedora.

Palavras-chave: Empreendedor. Comportamento de liderança. Orientação empreendedora. MPEs.

\begin{abstract}
The objective of this research is to analyze whether entrepreneurs' leadership behaviors in small and micro enterprises that provide services contribute to the dissemination of the many dimensions of entrepreneurial orientation. This is basic qualitative research of an exploratory and interpretative nature, carried out by means of interviews - with a semi-structured script - applied to five entrepreneurs who are MSE leaders. Research data was analyzed through content analysis proposed by Bardin (2008), and narratives, according to Gibbs (2009). The results reveal that entrepreneurs use the dimensions of entrepreneurial orientation with varying intensity and in an informal way, because they are not familiar with the practices of these dimensions.
\end{abstract}

Keywords: Entrepreneur. Behavior leadership. Entrepreneurial orientation. MSEs.

1. Doutorando em Engenharia Civil pela Universidade Estadual de Campinas (UNICAMP). [jonnybarreto@hotmail.com]

2. Doutora em Administração pela Universidade Presbiteriana Mackenzie. Professora e pesquisadora do Programa de Pós-Graduação Stricto Sensu da Universidade Nove de Julho (UNINOVE). [vania.nassif@uol.com.br]

Endereço dos autores: Faculdade FNC - Av Francisco Pignatari, 630, Cep. 06310-390 - Carapicuiba - SP - Brasil 


\section{RESUMEN}

Esta estudio tiene como objetivo analizar si el comportamiento de liderazgo del emprendedor en la micro y pequeńa empresa, proveedores de servicios, contribuye a la propagación de las dimensiones de la orientación emprendedora. Se trata de una base exploratoria cualitativa e interpretativa, llevada a cabo a través de entrevistas con un guión de estructura semiaplicada a cinco empresarios líderes de MPEs. Los datos de la investigación fueron analizados a través del análisis de contenido propuesto por Bardin (2008) y las teorías apoyadas por Gibbs (2009). Los resultados han demostrado que los emprendedores están utilizando la orientación emprendedora con intensidades diferentes y de manera informal, al no estar familiarizados con las prácticas de la orientación emprendedora.

Palabras clave: Emprendedor. Comportamiento de liderazgo. Orientación emprendedora. MPE.

\section{INTRODUÇÃO}

As empresas têm procurado, cada vez mais, absorver de seus colaboradores as competências e habilidades de que eles dispóem. Para que se tenha o efeito esperado, os colaboradores necessitam assimilar a cultura da empresa, os níveis de expectativas e o estilo de atuação dos gestores, líderes ou donos do negócio.

As dimensões da orientação empreendedora, discutidas por pesquisadores como uma estratégia que contribui para o estímulo e o desenvolvimento de competências e habilidades, além de potencializar as açôes dos colaboradores, vêm se mostrando como uma importante ferramenta de gestão dos líderes.

A utilização das dimensôes da orientação empreendedora, doravante intitulada $\mathrm{OE}$, contribui para que os processos empreendedores corporativos ocorram de maneira planejada e, assim, minimizem os impactos que diversos níveis de mudanças organizacionais podem provocar (MILLER, MILLER, 2011). São também entendidos como métodos, práticas e estilos de tomada de decisão gerencial usados para agir de forma empreendedora (LUMPKIN, DESS, 1996). Esses autores afirmam que a orientação empreendedora emerge de expectativas de escolhas estratégicas, cujas oportunidades de novos negócios podem ser empreendidas com sucesso de forma intencional.

Por outro lado, Covin e Lumpkin (2011), em um estudo desenvolvendo uma meta-análise sobre o tema, identificaram que o fenômeno da OE pode ser visto sob a ótica disposicional ou comportamental, evidenciando a dicotomia que existe nas empresas. Assim, para esses autores, ora as dimensóes da $\mathrm{OE}$ atuam como um dispositivo para incentivar o comportamento empreendedor, sem que suas lideranças estejam alinhadas com a prática desses incentivos, ora observa-se o comportamento espontâneo por parte dos funcionários, apesar de não haver respaldo institucional.

Assim, a OE envolve as intenções e ações, dos colaboradores-chave e também de lideranças, como um processo gerador de desenvolvimento entendido como uma postura empreendedora, propiciando, inclusive, uma dinâmica para a criação de novos negócios (COVIN, MILES, 1999).

As cinco dimensôes da $\mathrm{OE}$ são consideradas relevantes para guiar a prática de empreendedorismo, conforme Lumpkin e Dess (1996). São elas:

- capacidade inovadora, que está relacionada com o desempenho da organização (WIKLUND, 1999);

- propensão aos riscos, que trata o propósito de maximizar a relação risco-retorno (COVIN, SLEVIN, 1989; LUMPKIN, DESS, 1996);

- $\quad$ proatividade, que sugere a perspectiva de olhar para frente, acompanhada de atividades inovadoras (LUMPKIN, DESS, 1996);

- autonomia, que representa a ação independente dos indivíduos na organização (LUMPKIN, DESS, 1996); e,

- agressividade competitiva, que sugere açóes de superar a concorrência, combatendo ameaças do mercado (LUMPKIN, DESS, 1996).

Não obstante essas dimensóes serem apontadas como uma disposição de incentivar 
o comportamento empreendedor (COVIN, LUMPKIN, 2011), a liderança exercida pelo gestor é um fator determinante na disseminação das práticas da OE. Assim, a tipologia desenvolvida por Yukl, Gordon e Taber (2002) será a outra vertente de análise do presente estudo, tratando de três comportamentos que caracterizam o líder:

- comportamentos de tarefa: liderança voltada para operacionalização das atividades;

- comportamento de relacionamento: liderança voltada para coaching e desenvolvimento dos colaboradores; e

- comportamento de mudança: liderança que avalia os diversos ambientes que a empresa está inserida e tem foco em planejamento.

Dessa forma, o presente trabalho tem por objetivo analisar se o comportamento de liderança do empreendedor de micro e pequenas empresas, prestadoras de serviços, contribuem na disseminação das dimensões da orientação empreendedora. Como objetivos específicos, este estudo procurou conhecer o estilo de liderança de acordo com a taxonomia citada e identificar se o líder empreendedor utiliza ou não açôes relacionadas às dimensóes da $\mathrm{OE}$ na condução de suas atividades e, por consequência, no desenvolvimento dos colaboradores que o cercam.

\section{REFERENCIAL TEÓRICO}

A presente pesquisa contempla pressupostos teóricos orientados para analisar o comportamento de liderança do empreendedor na disseminação das dimensões da orientação empreendedora no contexto das organizaçôes.

Trata-se de um campo de estudo em ascensão; entretanto, quando o contexto é o de MPEs brasileiras, prestadoras de serviços, são poucos os trabalhos identificados, demonstrando assim uma lacuna e a existência de um campo de estudos a ser explorado. Dentre os estudos brasileiros, identificou-se uma pesquisa desenvolvida em empresas de grande porte, conceituadas e solidificadas no mercado do setor de software, com mais de dez anos de atuação, cujas dimensões da $\mathrm{OE}$ foram relevantes para impactar o negócio das empresas (MARTENS, 2009).

Um artigo desenvolvido por meio de pesquisa quantitativa procurou identificar semelhanças e diferenças de características entre empreendedores de incubadoras de empresas no Brasil e em Portugal, comparando os modelos de dimensóes culturais de Hofstede e de OE de Lumpkim e Dess, concluindo que existem diferenças entre as dimensôes culturais e que a $\mathrm{OE}$ se revelou mais elevada no Brasil do que em Portugal (SILVA, GOMES, CORREIA, 2009). O estudo de Reis Neto (2013) examinou o relacionamento dos constructos da OE, segundo abordagem de Naman e Slevin, e a capacidade de marketing no desempenho empresarial, percebido pelos gestores em empresas varejistas de Mato Grosso do Sul; os resultados apontaram que não existem diferenças significativas nas práticas da OE e da capacidade de marketing entre as empresas do tipo micro ou pequena. Os resultados, no entanto, sugerem que os empreendedores devem adotar uma postura mais empreendedora para conquistar maior desempenho empresarial.

Como se pode observar, dentro da literatura pesquisada ainda são poucos os estudos brasileiros voltados para OE em MPEs, sobretudo quando o objetivo se volta para a melhor compreensão da disseminação das dimensôes da OE por parte dos líderes empreendedores.

Desta forma, o artigo está organizado em quatro sessóes, além da introdução. $\mathrm{O}$ referencial teórico aborda as variáveis do estudo, o comportamento de liderança do empreendedor, sustentado pela taxonomia de Yukl, Gordon e Taber (2002), e a orientação empreendedora, apoiada nas cinco dimensóes de Lumpkin e Dess (1996). Na sequência, apresenta a metodologia, a natureza da pesquisa, os respondentes, o instrumento de coleta de dados e como esses dados foram tratados. Os resultados procuraram cruzar as variáveis, destacando as ações do líder empreendedor e a OE e, por fim, as consideraçôes finais, apresentando as limitaçóes, bem como as indicaçóes de futuros estudos. 


\section{I Comportamento de liderança do empreendedor}

A personalidade constitui um conceito que contribui para compreender as atitudes e os comportamentos dos indivíduos nas organizaçôes, além de sinalizar as diferenças individuais (MORIN, AUBÉ, 2009). Não obstante, um conjunto de comportamentos colaborou para a caracterização da liderança, bem como para as diversas formas de liderar (CHEMERS, FIELDLER, 1981). Essas açóes desencadeiam diferentes comportamentos na maneira de planejar, dirigir, controlar e supervisionar, apresentando variaçóes de uma situaçáo para outra.

“...a forma de liderar dos administradores é obviamente importante para o empregado e para a organização em geral. É importantíssimo para você se seu administrador lhe diz que você está realizando um bom trabalho e merece um aumento, ou que você é incompetente e deve ser demitido. $\mathrm{O}$ modo pelo qual o administrador se comporta com relação a seus subordinados influi no movimento total do trabalho, na satisfação dos empregados e, claro está, em seu desempenho..." (CHEMERS, FIELDLER, 1981, p. 35).
São várias as teorias que contribuem para analisar o perfil e o comportamento do líder perante seus colaboradores. Perren (2000) afirma que estudos de liderança têm sido associados ao empreendedor como uma das características fundamentais no processo de criação e desenvolvimento de negócios. Julien (2010) destaca as facetas do empreendedor sem se descuidar da história, da organização que o criou e do ambiente em que está inserido. Alguns trabalhos procuram explorar a amplitude das definiçóes de empreendedorismo e liderança, e há visôes concorrentes sobre as funçôes e os impactos causados por empreendedores e líderes.

Para efeito deste estudo, cujo intuito é o de analisar se o comportamento de liderança do empreendedor de MPEs, prestadoras de serviços, contribui na disseminaçáo das dimensôes da OE, foi escolhida a abordagem de Yukl, Gordon e Taber (2002), que sugerem uma taxonomia hierárquica. Essa taxonomia reflete a consolidação de três categorias, duas das quais são abordadas desde os primeiros estudos de liderança, como a abordagem comportamental (relacionamento e tarefa) e comportamentos de relacionamento, e uma terceira, que aborda aspectos relacionados com o ambiente externo (mudança), conforme apresentado no Quadro 1.

\begin{tabular}{|l|l|l|}
\hline Comportamentos de tarefas & Comportamentos de relacionamento & Comportamentos de mudança \\
\hline - Planeja atividades de curto prazo; & - Oferece suporte e encorajamento; & - Monitora o ambiente externo; \\
- Explicita os objetivos das tarefas e & - Reconhece realizaçóes e contribuiçôes; & - Propóe estratégias inovadoras ou \\
as expectativas sobre cada papel; e & - Desenvolve habilidades e a confiança dos liderados; & novas visóes; \\
- Monitora as operaçóes e a & - Consulta os liderados quando toma decisóes; & - Encoraja o pensamento inovador; e \\
performance. & - Dá aos liderados empowerment para que eles tomem & - Corre riscos para promover mudanças \\
\hline
\end{tabular}

QUADRO 1 - Taxonomia hierárquica de comportamento de liderança

Fonte: Yukl, Gordon e Taber (2002, p. 18).

Essa taxonomia propóe três aspectos que podem refletir o comportamento de líderes em relação às tarefas, ao relacionamento e às mudanças. Assim, essa abordagem explica as açōes que delimitam o ambiente interno e as atividades desenvolvidas pelos colaboradores (comportamentos de tarefas); o envolvimento com a equipe e o reflexo no seu desempenho (comportamento de relacionamento); e a percepção do ambiente externo e as açóes de mercado, envolvendo a equipe no desenvolvimento de atividades inovadoras ou novas estratégias para ganhar em competitividade (comportamentos de mudança).

\subsection{Orientaçáo empreendedora e suas dimensóes}

A OE é a prática do empreendedorismo dentro das organizaçôes. Tem como origem o 
planejamento estratégico, uma vez que está à luz das açôes dos indivíduos (MILLER, FRISEN, 1982). Especialistas consideram a OE como a maneira de gerir um negócio, ou seja, a empresa adota essa postura como forma de gestão empreendedora.

Assim, tem como característica buscar constantemente a inovação de produtos e tecnologia, a orientação agressiva competitiva e a forte tendência de os gestores assumirem riscos de negócio. Miller e Frisen (1982) argumentam que esse comportamento dos gestores ocorre periodicamente e é remetido para todos os níveis da organização, refletindo a filosofia global de negócio em ações práticas e tangíveis.

Uma das primeiras definiçóes de OE tratou justamente da gestão empreendedora que caracteriza uma organização empreendedora capaz de inovar em produtos e/ou mercados, com algum grau de risco no negócio e que atua de forma proativa diante de seus competidores (MILLER, 1983). Para consolidar essa linha de pensamento, a $\mathrm{OE}$ foi caracterizada pela composição de suas dimensōes. As três dimensóes iniciais identificadas nos estudos de Miller (1983) são: inovação, proatividade e propensão ao risco.

Inovação se refere à disponibilidade da empresa em apoiar e gerar possibilidades para que a criatividade e as experiências diversas sejam testadas em desenvolvimento de novos produtos e serviços, à introdução de novas tecnologias e à reengenharia de processos e procedimentos internos. Na visão de Miller e Frisen (1982), empresas empreendedoras se destacam pela forte utilização de práticas inovadoras. A segunda dimensão é a proatividade, entendida como a capacidade de a empresa buscar e desenvolver novas oportunidades e antecipar soluçóes e não simplesmente perseguir as opçôes de mercado disponíveis. Na prática, é antecipar as açôes, enxergar a oportunidade ou procurar pela resolução de um problema iminente. Para Lumpkin e Dess (1996), a proatividade está relacionada ao fato de o individuo antecipar suas ações em relação às necessidades que permearão o ambiente, controlando futuros problemas.

A propensão ao risco, terceira dimensão, trata a percepçáo da empresa em lidar com projetos que tenham perspectivas de novos negócios e, consequentemente, age de forma ousada em vez de cautelosa, com o intuito de atingir os objetivos da organização. Essa aceitação ao risco está diretamente relacionada ao interesse da alta cúpula da empresa em dispor de recursos na aplicaçáo de novos projetos e no desenvolvimento de novas oportunidades (LUMPKIN, DESS, 1996).

A partir de Miller (1983), Lumpkin e Dess (1996) submetem mais duas dimensōes para melhor caracterizar e abranger o processo empreendedor e as dimensóes da OE: agressividade competitiva e autonomia.

A agressividade competitiva, quarta dimensão, é caracterizada por ações que visam reduzir ou eliminar açóes da concorrência. Em sua maioria, relaciona-se a métodos não tradicionais de competição para obtenção do resultado esperado. Esses métodos tratam da opção de diminuir rentabilidade para ganhar parcela de mercado, atuar com preços abaixo dos concorrentes e agir conforme as ações dos concorrentes, respondendo de forma agressiva (VEKATARAMAN, 1989; CHEN, HAMBRICK, 1995).

Já a autonomia, quinta dimensão, diz respeito aos comportamentos que independe do empreendedor, refletindo nos colaboradores um comportamento guiado pelas práticas autônomas (LUMPKIN, DESS, 1996). É importante ressaltar que a adoção de tais práticas autônomas está diretamente ligada à postura da organização na liberdade das açóes que ela dispóe aos colaboradores. Bouchard (2002) cita a autonomia aos colaboradores como forma da expansão dos negócios, expandindo para fora da empresa a busca de oportunidades.

É relevante complementar que a cultura da empresa tem forte influência na disseminação dessas ações, sinalizando o quanto a empresa é capaz de desenvolver açóes independentes na busca de novas oportunidades, sem refletir constrangimento aos colaboradores que buscam tais iniciativas (LEE, PETERSON, 2000).

\section{PROCEDIMENTOS METODOLÓGICOS}

Essa pesquisa tem por objetivo analisar se o comportamento de liderança do empreendedor 
de MPEs prestadoras de serviços contribui na disseminação das dimensões da orientação empreendedora (OE). Para tal, as dimensóes de Lumpkin e Dess (1996) e a taxonomia de Yukl, Gordon e Taber (2002) alicerçaram teoricamente este estudo. Trata-se de uma pesquisa qualitativa básica que, segundo Merriam (1998), contém características essenciais da metodologia qualitativa, mas que náo possui todos os requisitos que possibilitem seu enquadramento como um estudo de caso, por náo visar uma análise detalhada do ambiente, ou ainda estudo etnográfico, por náo objetivar uma análise do comportamento dos membros do grupo, dentre outras modalidades específicas (GODOY, 2005).

A pesquisa é de natureza exploratória e, para esse tipo de pesquisa, o processo indutivo é o mais apropriado (BOOTH, COLOMB, WILLIAMS, 2005). Por se procurar pela compreensão de um fenômeno, o ponto de vista dos sujeitos pesquisados (líderes empreendedores) é fundamental, representando um ponto de partida para uma investigação (MARTINS, THEÓPHILO, 2009). A amostra selecionada para participar da pesquisa está localizada na regiáo oeste da grande São Paulo, levando em consideração a importância da região como propulsora de MPEs.

Os respondentes da pesquisa são cinco proprietários de MPEs prestadoras de serviços de diferentes ramos de atividade. Para levantamento de dados, optou-se pela entrevista em profundidade, apoiada por um roteiro semiestruturado.

Os dados foram gravados com autorização dos respondentes e transcritos na íntegra, visando propiciar reflexôes mais precisas e a fidelidade na interpretação das informaçóes coletadas (GIBBS, 2009). Na sequência, esses dados foram agrupados, categorizados e analisados por meio da análise de conteúdo proposta por Bardin (2008) e de narrativas, conforme Gibbs (2009). Assim, foi possível compartilhar o sentido que as experiências têm para os entrevistados e lhes dar voz para que expressem essas vivências, além de entender como encaram suas atividades profissionais e como lideram seus negócios.

\section{RESULTADO E ANÁLISE DOS DADOS}

Visando preservar a identidade das empresas e de seus respondentes, as companhias foram intituladas E1, E2, E3, E4 e E5. Para consolidação dos resultados, eles foram subdivididos em duas categorias: liderança e comportamento empreendedor e orientação empreendedora (OE).

\section{I Perfil dos respondentes e das empresas}

Os respondentes são empreendedores e os principais gestores das empresas pesquisadas, conforme o Quadro 2. Os critérios de seleção das empresas procuraram atender os seguintes requisitos: a) localizadas na região oeste da grande São Paulo e com tempo de existência acima de três anos; b) as características de negócio e/ou inserção no mercado identificam algumas ações empreendedoras; c) o porte da empresa caracterizado segundo a Lei Complementar n. 123 de 14 de dezembro de 2006; e, d) por acessibilidade.

\begin{tabular}{|c|c|c|c|c|c|c|}
\hline $\begin{array}{c}\text { Gestor / } \\
\text { Empresa }\end{array}$ & Instruçáo & Cargo & $\begin{array}{c}\text { Experiência / } \\
\text { anos }\end{array}$ & Localizaçáo & $\begin{array}{c}\text { No de } \\
\text { funcionários }\end{array}$ & Ramo de atividade \\
\hline E1 & Pós-graduaçáo & Diretor & 16 & Osasco & 5 & Consultoria em geral \\
\hline E2 & $1^{\text {o }}$ grau completo & Diretor & 4 & Carapicuíba & 6 & Comércio de paletes \\
\hline E3 & $3^{\text {o } g r a u ~ c o m p l e t o ~}$ & Diretor & 20 & Osasco & 15 & Logística internacional \\
\hline E4 & $3^{\text {o grau completo }}$ & Diretor comercial & 7 & Barueri & 10 & Logística nacional \\
\hline E5 & Pós-graduaçáo & Diretor comercial & 20 & Osasco & 10 & Avaliaçáo patrimonial \\
\hline
\end{tabular}

QUADRO 2 - Perfil dos respondentes e das empresas

Fonte: Dos autores. 
O Quadro 2 apresenta os dados demográficos dos respondentes da pesquisa, evidenciando o bom nível educacional desses líderes empreendedores. Observa-se que os anos de experiências são significativos, sinalizando a superação dos três anos de sobrevivência, marco de mortalidade de micro e pequenas empresas, conforme pesquisa do Sebrae (2012). Quanto à localização, a região oeste da grande São Paulo foi escolhida para a pesquisa pelo crescimento acentuado nos últimos anos, facilitados por incentivos fiscais e forte atuação em prestação de serviços para a população, além de ser considerada como regiáo propulsora de MPEs.

\subsection{Categorias de respostas}

Os dados foram categorizados procurando agrupar as respostas e classificá-las de acordo com as dimensões da OE conforme Lumpkin e Dess (1996), e da taxonomia de liderança, segundo
Yukl, Gordon e Taber (2002). Após várias leituras e seguindo as orientaçôes de Bardin (2008), as categorias consolidadas ficaram assim definidas: 1) liderança e comportamento empreendedor, 2) dimensôes da orientação empreendedora.

\subsection{Categoria 1: Liderança e comportamento empreendedor}

Essa categoria avalia as ações e comportamentos empreendedores, refletidos através da forma de liderar e de agir e do entendimento sobre a percepção de empreendedorismo dentro das empresas pesquisadas. Para consolidar tais informações, este trabalho propôs a separação por tópicos para melhor compreensão das respostas geradas. O Quadro 3 traz a compreensão dos respondentes sobre a percepção do que é empreendedorismo e açôes empreendedoras desenvolvidas dentro das empresas.

\begin{tabular}{|c|c|c|}
\hline Empreendedor & Percepçáo de empreendedorismo & Açóes empreendedoras \\
\hline E1 & $\begin{array}{l}\text { “...é um dom natural da pessoa. } \\
\text { Não precisa ser o dono, por isso há no mercado pessoas } \\
\text { que comandam e as pessoas que são comandadas." }\end{array}$ & $\begin{array}{c}\text { "...em empresas como a minha, } \\
\text { ela já é o empreendedorismo por si. A consultoria sempre } \\
\text { tem que propor soluçôes, e os problemas não são iguais, } \\
\text { então se não tiver as características do empreendedorismo, } \\
\text { você não sai do lugar.” }\end{array}$ \\
\hline E2 & $\begin{array}{l}\text { "É ampliar, construir, pensar grande, } \\
\text { se vai conseguir não sei, mas tem que pensar grande." }\end{array}$ & $\begin{array}{l}\text { "...o trabalho que você faz, o minimo que seja, } \\
\text { está contribuindo para empreender, com certeza." }\end{array}$ \\
\hline E3 & $\begin{array}{l}\text { "...aprendi um pouco ser empreendedor com meu pai [...] ele } \\
\text { me mandava vender alguma coisa na feira. Ele comprou uma } \\
\text { máquina de picolé e eu saía para comercializá-lo. Quando } \\
\text { estava me formando, comecei a enxergar que anos atrás meu } \\
\text { pai estava me ensinando ser empreendedor." }\end{array}$ & $\begin{array}{l}\text { “..é buscar o mercado e buscar o resultado do seu } \\
\text { trabalho, é mostrar que você pode fazer e fazer bem feito, } \\
\text { mesmo que seja um negócio pequeno." }\end{array}$ \\
\hline E4 & $\begin{array}{l}\text { "...é você ter garra, só que baseado em fatos, não é simples- } \\
\text { mente eu gosto disso e vou fazer." }\end{array}$ & $\begin{array}{l}\text { "... a linha de comunicação e responsabilidade } \\
\text { perante o cliente o mais aberta possivel." }\end{array}$ \\
\hline E5 & $\begin{array}{c}\text { "É a habilidade de lidar com o negócio, é agregar valor ao } \\
\text { mercado pela sua empresa e assumir risco desse negócio. } \\
\text { Náo é simplesmente colocar uma ideia em prática, } \\
\text { mas é consolidar essa ideia." }\end{array}$ & $\begin{array}{c}\text { "...entender de que forma você pode abordar o cliente, } \\
\text { oferecer seu trabalho, criar caminhos onde o cliente } \\
\text { possa se beneficiar desse trabalho." }\end{array}$ \\
\hline
\end{tabular}

QUADRO 3 - Percepçôes de empreendedorismo e açôes empreendedoras

Fonte: Dos autores.

As diferentes percepções de empreendedorismo que a literatura apresenta também são destacadas pelos respondentes. Apesar de se considerarem empreendedores, há certa dificuldade quando indagados sobre o que é empreendedorismo e como se identifica uma ação empreendedora.
De qualquer maneira, as diferentes percepçóes apontam para um indivíduo com capacidade para liderar equipes, que pensa grande e tem aspiraçôes, pode não ter influências de outras pessoas para a abertura de seu negócio, mas se inspira em outras pessoas pelas contribuiçōes recebidas e isso 
ajuda na formação empreendedora. Ter garra e disposição para executar as atividades com sabedoria e habilidade e ser capaz de gerir um negócio, consolidando a ideia e estando ciente dos riscos inerentes, são características também apontadas por eles.

Os respondentes evidenciam características de empreendedores inovadores, já que a busca para mudar algo que não está em acordo com a expectativa dos clientes parece ser o principal fator para criação do negócio. Esses dados corroboram os pressupostos de Bessant e Tidd (2009), Degen (2009) e Julien (2010) ao afirmar que o empreendedor é aquele que realiza coisas novas e assumem riscos. De maneira complementar, Kirzner (1973) e Salim (2004) definem o empreendedor como aquele que encontra oportunidade em ambiente de caos, identifica quando o mercado dá sinais de alguma demanda não atendida e visualiza esse contexto como oportunidade, além de ser uma pessoa capaz de liderar e que tem conhecimento sobre o ramo de negócio (SHANE, VENKATARAMAN, 2000).

Como as ações empreendedoras são guiadas pelo estilo de seus líderes, esse estudo foi apoiado nas taxonomias de liderança propostas por Yukl, Gordon e Taber (2002), caracterizadas pelo estilo de gestão, comportamentos de tarefa, de relacionamento e de mudança. Se a forma de liderar reflete na produtividade dos colaboradores, todos os respondentes atestam que sua liderança é participativa e cordial e que isso é percebido pelos colaboradores. Afirmam ainda que "os colaboradores têm liberdade para trabalhar e se consideram como donos do negócio” (E5), “os colaboradores passam confiança” (E3), "o relacionamento interpessoal com os colaboradores está além das fronteiras da empresa" (E1) e que "eles são tratados de forma afetiva” (E2). A empresa E4 define o relacionamento entre empreendedor e colaboradores.

Nós estamos sempre conversando e estar próximo no dia a dia deles já é atrativo, porque há situaçóes em que eles ficam muito mais à vontade comigo do que qualquer outro chefe que tiveram em outras empresas, por quê? Porque sempre tive respeito e comprometimento com eles. (E4)

As características de líderes observadas na literatura estão em conformidade com a visão de liderança mencionada pelos respondentes. Perren (2000), dentre outras características, afirma que a liderança está associada com comunicação e habilidades sociais, confiabilidade, confiança inspiradora, real interesse nos outros e orientação para equipe. Mintzberg, citado por Yukl (1998), relaciona os chamados papéis do líder, dentre alguns fatores, como os papéis interpessoais, mantendo relações sociais com os grupos.

\subsubsection{Categoria 2: Dimensóes da Orientação Empreendedora (OE)}

A categoria 2 foi analisada sob a perspectiva das cinco dimensóes da $\mathrm{OE}$ propostas por Lumpkin e Dess (1996), que segundo eles constituem a prática da OE nas organizaçóes. São elas: inovação, propensão ao risco, proatividade, autonomia e agressividade competitiva. As dimensões serão apresentadas, uma a uma, e no final dessa sessão uma discussão foi realizada, procurando refletir as respostas à luz da literatura estudada.

\subsubsection{Inovaçâo}

Essa dimensão considera como inovadoras as açóes dos indivíduos, a inserção de novos produtos e serviços ou simplesmente a mudança de uma forma de atuar para outra, com o intuito de aumentar competitividade.

Nesse sentido, a base para interpretar essa dimensão é analisar o surgimento das inovaçóes, o desenvolvimento dos negócios dentro das MPEs e a interação entre gestores e colaboradores na disseminação de ideias e na implantação de processos inovadores.

O Quadro 4 apresenta as principais consideraçóes acerca do assunto na visão dos empreendedores líderes. 


\begin{tabular}{|c|c|c|}
\hline Empreendedor & Surgimento das inovaçóes & Os negócios e a inovaçáo na empresa \\
\hline E1 & $\begin{array}{l}\text { - Implementar novas } \\
\text { formas de atuação } \\
\text { constantes e trocar ideias } \\
\text { com especialistas no } \\
\text { desenvolvimento } \\
\text { de algo novo. }\end{array}$ & $\begin{array}{l}\text { “Os negócios são feitos através de um site que eu tenho...” } \\
\text { “...eu participo de palestras e feiras... É nesse ambiente que você pode } \\
\text { fazer networking e através desse networking conseguir um negócio." } \\
\text { - Inovaçáo aconteceu quando da personalizaçáo de um produto } \\
\text { que levou a uma grande exposição no mercado. }\end{array}$ \\
\hline E2 & $\begin{array}{c}\text { - Melhorar sempre a } \\
\text { qualidade do serviço } \\
\text { prestado. }\end{array}$ & $\begin{array}{c}\text { “...mas você tem o jeito de captar, agradar, de entrar } \\
\text { na empresa, para conquistar o cliente..." } \\
\text { "Eles (colaboradores) vêm com a ideia e você analisa, conversa e } \\
\text { vamos colocar em prática. Foi bom? Deu certo? Parabéns." } \\
\text { - Inovação aconteceu quando mudou a maneira de reformar o palete e } \\
\text { houve queda nas manutençóes do cliente, gerando fidelidade. }\end{array}$ \\
\hline E3 & $\begin{array}{l}\text { - Por experiência } \\
\text { com base nos projetos } \\
\text { implantados e naqueles } \\
\text { que não deram certo. }\end{array}$ & $\begin{array}{c}\text { “...analisando o processo que você faz hoje, você o modifica para que } \\
\text { ele seja mais rápido, isso você pode usar operacional ou comercialmente...” } \\
\text { “...as ideias surgem de necessidades quando você náo está contente com determinados } \\
\text { assuntos ou algo que te faça trabalhar demais ou fazer um retrabalho." } \\
\text { - Inovação aconteceu quando foi desenvolvido um novo modelo de } \\
\text { negócios de transporte internacional, com grades de entrega (com previsão } \\
\text { de implantação para segundo semestre de 2011) }\end{array}$ \\
\hline E4 & $\begin{array}{l}\text { - Em discussóes semanais } \\
\text { para correção e análise da } \\
\text { operação, além da troca de } \\
\text { ideias no dia a dia. }\end{array}$ & $\begin{array}{l}\text { “...com o passar do tempo, vai surgindo uma parceria, nós começamos } \\
\text { a fazer uma análise como está sendo o atendimento, o negócio atual..." } \\
\text { "... a gente inclui uma reunião com os colaboradores para ouvir as } \\
\text { dificuldades em que eles se encontram e quais são as soluçóes...” } \\
\text { - Inovaçáo aconteceu quando um colaborador realocou seu } \\
\text { veículo em outra rota, gerando maior produtividade. }\end{array}$ \\
\hline E5 & $\begin{array}{l}\text { - Da necessidade de } \\
\text { agregar valor ao cliente e } \\
\text { na busca constante para } \\
\text { reduzir prazos, que é um } \\
\text { diferencial de negócio. }\end{array}$ & $\begin{array}{c}\text { “...os negócios surgem de observar o mercado.” } \\
\text { “...surgem principalmente dos problemas que o cliente traz e quando } \\
\text { consigo reduzir prazo, eu consigo trazer algo novo para a empresa.” } \\
\text { - Inovaçáo aconteceu quando profissionais de TI desenvolveram um } \\
\text { novo sistema para auxiliar e criar dinamismos nas análises. }\end{array}$ \\
\hline
\end{tabular}

QUADRO 4 - Dimensão inovação

Fonte: Dos autores.

A inovação dentro das MPEs prestadoras de serviços ainda parece ser algo de difícil compreensão e alcance por parte dos empreendedores. Não há clareza do processo e desenvolvimento da inovação por parte dos respondentes; no decorrer das entrevistas foram necessários repetidos questionamentos para se conseguir atingir, de alguma forma, a compreensão do conceito de inovação, mesmo para os empreendedores convictos de que são inovadores.

\subsubsection{Propensão ao risco}

A segunda dimensão explora a propensão ao risco e seu impacto nos negócios das MPEs. A propensáo ao risco trata da capacidade de o empreendedor assimilar possíveis perdas nos negócios, atuar em situaçôes diversas sem ter conhecimento se o resultado será satisfatório e tomar decisóes que podem ou não estar relacionadas com dinheiro
(BHIDÉ, 2004). Sugere ainda uma dimensão direcionada aos gestores, refletindo em sua forma de atuar. Lumpkin e Dess (1996) afirmam que essa é a dimensão da OE mais importante, pelo grau de envolvimento com o caminho que a empresa segue no mercado.

Nesse sentido, para analisar esse impacto nas MPEs pesquisadas, foi indicada uma análise voltada para as perspectivas de mudança de ambiente, aplicabilidade de projetos diversos nas empresas, tomada de decisão que pode estar relacionada com dinheiro e a visão de seu negócio perante o mercado. O Quadro 5 apresenta as principais considerações acerca dessa dimensão. Para tal, procurou-se classificar os itens dentro de uma escala qualitativa, cujas propensões variam entre moderado, agressivo e conservador. Além disso, procurou-se identificar se os respondentes consideram a mudança como um risco. 


\begin{tabular}{|c|c|c|c|c|c|}
\hline Item & E1 & E2 & E3 & E4 & E5 \\
\hline Projeto & Moderado & Moderado & $\begin{array}{c}\text { Moderado } \\
\text { para agressivo }\end{array}$ & $\begin{array}{c}\text { Conservador } \\
\text { para moderado }\end{array}$ \\
\hline Risco de negócio & Agressivo & $\begin{array}{c}\text { Moderado } \\
\text { para agressivo }\end{array}$ & Agressivo & Moderado & Moderado \\
\hline $\begin{array}{c}\text { Considera a } \\
\text { mudança um risco }\end{array}$ & $\operatorname{Sim}$ & $\operatorname{Sim}$ & Não & $\operatorname{Sim}$ & Sim \\
\hline
\end{tabular}

QUADRO 5 - Propensão ao risco

Fonte: Dos autores.

Essa dimensão traz consigo considerações valiosas do ambiente da empresa, por tratar a forma de atuaçáo dos gestores. Ao considerar os tipos de projetos que são inseridos nas MPEs, os empreendedores refletem seu grau de exposição, que é um dos fatores críticos dessa dimensão. $\mathrm{O}$ grau de exposição adotado por essa pesquisa é o modelo das aplicaçôes financeiras, que considera um grau conservador quando não há qualquer risco que comprometa os negócios (a caderneta de poupança, por exemplo), moderado quando considera certa flexibilidade, assumindo algum risco (investimento em fundos de pensão, por exemplo), e agressivo quando o risco é algo factível na atividade (açôes negociadas na Bolsa, por exemplo).

De qualquer maneira, a atuação das empresas pesquisadas está concentrada no grau moderado. Esses achados da pesquisa estão em conformidade com a literatura. Os empreendedores líderes procuram não se arriscar demasiadamente. Covin e Slevin (1989) citam que os gestores têm tendência para projetos de baixo risco. Bhidé (2004), afirma que os empreendedores não arriscam tanto, mas toleram como poucos conviver com a incerteza e a ambiguidade. Esses autores pontuam que os gestores preferem explorar o ambiente de maneira gradual, com cautela. A resposta da empresa E3 retrata essa necessidade de análise do ambiente.

A gente faz o que muitas empresas de grande porte não fazem, então existe certo receio de que a gente vá crescer acima das expectativas, então trabalhamos com o freio de mão puxado para crescer dentro do esperado. O nosso interesse maior é aumentar a receita líquida, deixar de ter fornecedores (terceiros) e implementar algo jamais visto no mercado e estamos otimizando o projeto em um todo. (E3)

Apesar de atuarem de forma moderada, com cautela, os empreendedores consideram o risco de negócio elevado. Mesmo uma empresa propensa a seguir o mercado e suas leis, como sugere o empreendedor (E5), precisa restringir o comportamento mais agressivo para sobreviver. Por isso, procura trabalhar sob a tutela de risco moderado para seus negócios.

Segundo Dess e Lumpkin (2005), o risco do negócio está atrelado ao desconhecimento do mercado, à falta de informaçôes sobre financiamento bancário, sem garantia de retorno, e ainda ao risco pessoal que acaba por adotar uma estratégia e se manter nela. Os respondentes das empresas E2 e E3 corroboram essa informação.

Esse trabalho é mais ou menos assim, agressivo... Tem momento que dá impressáo de que você vai ganhar, você vai ter retorno, em outros que vai ficar sem nada, então entra a parte que você tem que ter certo equilibrio para agir na hora que você está bem. (E2)

Agressivo, porque hoje o cliente ele não é considerado "meu", ele é do mercado. Se você não fideliza e não transparece o que se faz e não presta um bom serviço, amanhã ele pode "estar trabalhando" com outro, mesmo que náo seja dentro do teu projeto. Então, o mercado é agressivo em ralação a isso, você é que tem que saber administrar essa carteira e a empresa para que ela possa dar suporte nas vendas, manutençâo de cliente $e$ operação. (E3) 
Com relação à mudança, todos os respondentes a consideram um risco associado a uma nova oportunidade de negócio. Por ser algo que pode estar fora de seu controle, é aceito sem muitos questionamentos. O respondente da empresa E2 retrata o receio de mudar, apesar de entender que se faz necessário para o crescimento de seu negócio. Já E4 enfatiza que, se não mudar, pode ter um risco de perda de competitividade e consequente perda de mercado. $\mathrm{O}$ respondente da empresa E5 simboliza a percepção dos gestores quando relata a mudança.

“...uma oportunidade é um risco, mas é também uma grande oportunidade para aprender, para se adaptar, fugir das nossas próprias resistências". (E5)

\subsubsection{Proatividade}

A terceira dimensão explora a proatividade e seu impacto nos negócios. É a capacidade de enxergar uma oportunidade antes que ela aconteça ou simplesmente se antecipar a um problema para que ele seja reduzido ao máximo ou eliminado.

É uma iniciativa em antecipar e perseguir novas oportunidades, como participar de mercados emergentes (LUMPKIN, DESS, 1996). Em um nível estratégico, Miller e Friesen (1978), interpretam a proatividade como a capacidade de moldar o ambiente com novos produtos e serviços. Nesse sentido, a base para a interpretação da proatividade dentro das MPEs é a análise do mercado e dos concorrentes, a postura do gestor perante o mercado, a forma de controlar os negócios e a resposta perante novas açóes no mercado. Para melhor compreensão, o Quadro 6 apresenta as considerações acerca dessa dimensão.

\begin{tabular}{|c|c|c|}
\hline \multirow{2}{*}{ Empreendedor } & \multicolumn{2}{|c|}{ Análise do negócio } \\
\hline & Ambiente externo & Ambiente interno \\
\hline E1 & $\begin{array}{l}\text { - Concorrência em larga escala; } \\
\text { - Excelência ou saída do mercado } \\
\text { - Observaçáo da dinâmica do mercado } \\
\text { - Pensamento como empresa global }\end{array}$ & $\begin{array}{l}\text { - Controle de negócios centralizado } \\
\text { - Tomada de decisão embasada em critérios preestabelecidos } \\
\text { - Gestão descentralizada e centralizada em vários pontos } \\
\text { (responsáveis) }\end{array}$ \\
\hline E2 & $\begin{array}{l}\text { - Atenção com a concorrência desleal } \\
\text { - Aumento da qualidade para consolidar mercado }\end{array}$ & $\begin{array}{l}\text { - Controle de negócios em planilhas } \\
\text { - Gestáo descentralizada como forma de não sobrecarregar }\end{array}$ \\
\hline E3 & $\begin{array}{l}\text { - Foco nas empresas grandes } \\
\text { - Flexibilidade para se diferenciar } \\
\text { - Saída de posição defensiva }\end{array}$ & $\begin{array}{l}\text { - Controle de negócios em estruturação } \\
\text { - Gestão em descentralizaçãa (aumento de confiança com a } \\
\text { equipe) }\end{array}$ \\
\hline E4 & $\begin{array}{l}\text { - Comunicação e informação são diferenciais de } \\
\text { mercado } \\
\text { - Trabalho no erro dos concorrentes } \\
\text { - Ética com os concorrentes }\end{array}$ & $\begin{array}{l}\text { - Controle de negócios em planilhas } \\
\text { - Gestão descentralizada entre os sócios }\end{array}$ \\
\hline E5 & $\begin{array}{l}\text { - Concorrência forte, respeitável; } \\
\text { - Preço determina fechamento de novos negócios } \\
\text { - Empresas não profissionalizadas têm vida curta }\end{array}$ & $\begin{array}{l}\text { - Controle de negócios em módulos de sistemas; } \\
\text { - Boa gestão em contas a receber e pagar; e } \\
\text { - Gestão descentralizada (direcionada ao gerente do projeto) }\end{array}$ \\
\hline
\end{tabular}

QUADRO 6 - Proatividade

Fonte: Dos autores.

A análise do ambiente é fundamental para que o empreendedor possa se antecipar ao mercado e aproveitar possíveis oportunidades que se apresentem ou atuar em situaçôes em que as MPEs necessitem de correção. Nesse sentido, os respondentes se mostraram conhecedores do mercado e de seus concorrentes. "O mercado conta hoje com muitos concorrentes" (E1), "há necessidade de se preocupar com suas açôes” (E2), "meus concorrentes são fortes e respeitáveis" (E5), "tem muitos concorrentes desleais" (E2). Assim, os empreendedores pontuaram como ponto de 
atenção a necessidade de observar a dinâmica do mercado e de seus concorrentes.

\subsubsection{Autonomia}

A quarta dimensão é a autonomia e a maneira de agir dos gestores e dos colaboradores. A autonomia está relacionada com a liberdade de ação dos colaboradores e dos gestores na execução das atividades. Burgelman (2001) afirma que a autonomia é parte inerente ao processo empreendedor e, dessa forma, pode contribuir para que a empresa ganhe mercado por sugerir maior envolvimento dos colaboradores. Por outro lado, Burns
(1978) destaca que a liderança transformadora está relacionada ao desenvolvimento da capacidade do líder e à educação dos subordinados, a fim de que sejam estimulados a se tornarem independentes dos líderes, para desenvolverem seus talentos e sua motivação. Desse modo, a base para a interpretação da percepção da autonomia dentro das MPEs é a visão dos líderes na delegação das atividades e o comportamento percebido dos colaboradores no incentivo às práticas autônomas e no monitoramento dessas atividades no sentido de deixá-los agir, mas também colaborar e auxiliar nas ações a serem desenvolvidas. O Quadro 7 apresenta as principais consideraçôes dessa dimensão.

\begin{tabular}{|c|c|c|c|}
\hline Empreendedor & $\begin{array}{c}\text { Concessáo de autonomia } \\
\text { aos colaboradores }\end{array}$ & $\begin{array}{c}\text { Monitoramento das } \\
\text { atividades autônomas }\end{array}$ & Percepção de autonomia nos negócios \\
\hline E1 & Sim & $\begin{array}{c}\text { Por trabalho, centralizando } \\
\text { as informações }\end{array}$ & $\begin{array}{l}\text { A autonomia está relacionada à responsabilidade, que } \\
\text { contribui para um melhor desenvolvimento da empresa. }\end{array}$ \\
\hline E2 & Observação & $\begin{array}{l}\text { A autonomia deixa o colaborador mais livre para } \\
\text { trabalhar, náo gera insatisfaçáo e náo se sente controlado. }\end{array}$ \\
\hline E3 & Sim & Relatórios & $\begin{array}{l}\text { A autonomia contribui no relacionamento com os clien- } \\
\text { tes, além de o colaborador opinar e apresentar soluçóes. }\end{array}$ \\
\hline E4 & Sim & Não há controle formal & $\begin{array}{l}\text { Abre um canal de comunicação com os } \\
\text { gestores e isso faz fluir o trabalho. }\end{array}$ \\
\hline E5 & Monitorando as açóes & $\begin{array}{l}\text { Proporciona condiçóes para o colaborador gerir } \\
\text { o negócio de maneira natural. }\end{array}$ \\
\hline
\end{tabular}

QUADRO 7 - Autonomia

Fonte: Dos autores.

De acordo com os líderes empreendedores, a autonomia pode trazer vantagens para os negócios da empresa, além de acreditarem ser esse um fator importante no desenvolvimento das atividades. É tratada como um acréscimo de responsabilidade (E1), "como uma melhoria da relação cliente-fornecedor" (E3), "pode gerar um menor grau de insatisfação do colaborador" (E2) e "estreitar de maneira natural a relação gestor-colaborador" (E4), além de "desenvolver habilidades de gestão" (E5).

Bouchard (2002) destaca outra abordagem denominada autonomia meta, quando a empresa sugere, inclusive fora de suas restriçôes organizacionais, autonomia aos colaboradores para buscarem novas alternativas para os negócios. Se essa autonomia é positiva para a empresa, a forma de atuar dos gestores pode sugerir certo descontrole sobre as atividades, por isso há necessidade de monitoramento constante das atividades autônomas relatadas pelos colaboradores. $\mathrm{O}$ respondente da empresa E5 ratifica essa informação.

Na verdade, temos dois tipos de colaboradores. O colaborador CLT, aquele que trabalha conosco o tempo todo - nesse caso, acho que uns dez -, e o colaborador por projeto. Esse colaborador tem total liberdade, tem autonomia, existem algumas regras básicas, normas nada assim demais, mas às vezes o cara que é novo, ele vê o ambiente e acha que pode fazer o quiser e depois ele percebe que tem resultados para atingir. Então, no primeiro momento, ele acha que a coisa é desorganizada, depois que começam as cobranças, os prazos, ele vai perceber que 
é diferente, ele pode fazer do jeito que achar melhor, mas se estourar o prazo, ele sabe que será cobrado. Mas do processo ele faz toda gestão. Às vezes, demora em entender, mas depois ele percebe que as coisas acontecem pelo processo dele mesmo, de forma natural. (E5)

Essa forma de atuar é destacada por Dess e Lumpkin (2005) como elementos que caracterizam autonomia e é descrita como o encorajamento do pensamento empreendedor, o estímulo para desenvolver novas ideias, para desenvolver equipes autônomas e, consequentemente, a monitoraçáo das atividades.

\subsubsection{Agressividade competitiva}

A última categoria de análise centra na dimensão da agressividade competitiva. Nessa dimensão, procura-se analisar o comportamento do empreendedor frente aos concorrentes e ao mercado. Tem como foco as açóes na conquista de novos mercados ou na expansão do mercado atual, denominado agressividade competitiva. Essa dimensão é exemplificada na postura agressiva para combater tendência, no uso de métodos incomuns (DESS, LUMPKIN, 2005) ou, ainda, em possíveis sacrifícios financeiros (VENKATARAMAN, 1989).

Nesse sentido, a base para a interpretação da percepção da agressividade competitiva é o entendimento sobre o conceito de agressividade competitiva, as formas de condução na busca de aumento de parcela de mercado e ações que inibem o crescimento dos concorrentes. O Quadro 8 apresenta as principais consideraçôes acerca dessa dimensão.

\begin{tabular}{|c|c|c|c|}
\hline Empreendedor & $\begin{array}{l}\text { Açóes para } \\
\text { crescimento } \\
\text { próprio }\end{array}$ & $\begin{array}{l}\text { Açóes para inibir } \\
\text { crescimento dos } \\
\text { concorrentes }\end{array}$ & Conceituaçáo de agressividade competitiva \\
\hline E1 & Networking & Ser observador & $\begin{array}{l}\text { "Marketing, credibilidade, honestidade, } \\
\text { presteza e o principal, competência do negócio." }\end{array}$ \\
\hline E2 & $\begin{array}{l}\text { Crescimento } \\
\text { estrutural }\end{array}$ & Ser competente & $\begin{array}{c}\text { "Competência, você tem que ser muito competente, para ser agressivo } \\
\text { em seu negócio, caso contrário não apresenta soluçôes para a empresa. } \\
\text { Boa parte da agressividade do mercado é reconhecida e estará traçada. } \\
\text { Então cabe ao gestor entender tudo isso." }\end{array}$ \\
\hline E3 & $\begin{array}{l}\text { Investimento } \\
\text { em novos } \\
\text { setores }\end{array}$ & $\begin{array}{l}\text { Ser eficiente e } \\
\text { responsável }\end{array}$ & $\begin{array}{c}\text { "Quando você mostra eficiência e responsabilidade os clientes te procuram. } \\
\text { Isso acaba se tornando aos olhos de seus concorrentes uma açáo agressiva, } \\
\text { ou seja, ele pensa... Aquela empresa lançou um produto e esse produto está } \\
\text { chamando muita atenção pela qualidade, pelo preço e pela rapidez. } \\
\text { Säo esses aspectos que são entendidos como agressivos aos olhos de } \\
\text { quem está de fora. Não significa que vou destruir os concorrentes, } \\
\text { mas o opositor percebe dessa forma." }\end{array}$ \\
\hline E4 & $\begin{array}{l}\text { Atuação no } \\
\text { erro do } \\
\text { concorrente }\end{array}$ & $\begin{array}{l}\text { Ser inovador e } \\
\text { arrojado }\end{array}$ & $\begin{array}{l}\text { "Uma empresa inovadora é uma empresa arrojada, mesmo sendo } \\
\text { conservadora. Ela faz algo novo no mercado ou toma uma atitude } \\
\text { inovadora, que outras não fazem. Mas náo fazem por quê?? } \\
\text { Porque têm dificuldades, e é onde você tem que ter garra para fazer." }\end{array}$ \\
\hline E5 & Parcerias & Ser ágil & $\begin{array}{l}\text { "Eu acho que uma empresa competitiva é aquela que consegue oferecer } \\
\text { muitos diferenciais competitivos, bem geridos. Eu chamo de bem gerido } \\
\text { da seguinte forma: todo mundo entrega um relatório no final, então nós } \\
\text { colocamos informaçóes que ajudam ainda mais na tomada de decisāo do } \\
\text { cliente. Precisa estar sensivel nessa avaliação para entender o cliente. } \\
\text { Na empresa competitiva você vai mostrar seu trabalho. Na abordagem } \\
\text { é da mesma maneira, a abordagem é extremamente técnica." }\end{array}$ \\
\hline
\end{tabular}

QUADRO 8 - Agressividade competitiva

Fonte: Dos autores. 
Nessa dimensão, os respondentes expóem características que podem ser próprias e inseridas no ambiente da empresa, evitando mencionar ações que possam gerar dúvidas sobre ética nos negócios ou gerar algum tipo de instabilidade de relacionamento com concorrentes.

Observa-se que as características próprias podem ser associadas à honestidade e à credibilidade (E1), competência (E2), eficiência (E3), garra (E4) e sensibilidade (E5).

Não obstante a maioria das pesquisas estarem voltadas para empresas de grande porte, essas características pessoais não aparecem como características nas MPEs. São retratados como agressividade competitiva os gastos em marketing, qualidade de serviço, conforme Macmillan e Day (1987), citados por Dess e Lumpkin (2005). Ou ainda cortar preços para aumentar participação de mercado (VENKATARAMAN, 1989) e adotar postura de desestruturar o concorrente (DESS, LUMPKIN, 2005). Para o crescimento de negócio, as MPEs pesquisadas buscam, principalmente, relacionamento, gerando um bom contato com seus clientes, na captação por meio de indicação. Açóes como networking (E1) e parcerias (E5) refletem essa forma de agir. Os respondentes das empresas E4 e E5 estabelecem esse envolvimento com clientes.

Sempre buscamos trabalhar em cima da falha do concorrente, então a gente estuda sempre mediante os clientes entenderem quais as dificuldades que eles estáo encontrando. Hoje, se tem uma praça que está sendo mal atendida, que talvez não faça, que a partir dai possa fazer, tentar náo cometer o mesmo erro. Vou citar um exemplo hoje, que é um cliente que náo fazia a praça de São Paulo conosco. Devido a uma situação que eles estavam com dificuldade com outro concorrente, quando eles souberam que nós estávamos fazendo, nós questionamos também o porquê de não fazer com a gente. Nós propusemos a oferta $e$ eles aceitaram... A gente sempre conduz essas melhorias. (E4)

Eu acho que uma empresa competitiva é aquela que consegue oferecer muitos diferenciais competitivos, bem geridos. Eu chamo de bem gerido da seguinte forma: Todo mundo entrega um relatório no final, entâo nós colocamos informaçóes que ajudam ainda mais na tomada de decisáo do cliente. Precisa estar sensivel nessa avaliação para entender o cliente. Se tornar a empresa competitiva, você vai mostrar o seu trabalho. (E5)

Para as MPEs, o networking é a principal fonte de novos negócios, segundo os respondentes. Ele é fundamental também no estreitamento das relaçôes e na expansão dos negócios já existentes. Não foi possível identificar na literatura estudos que associam a agressividade competitiva ao networking, como uma forma de ganhar mercado ao mesmo tempo que reduz participação do concorrente. $\mathrm{O}$ respondente da empresa $\mathrm{E} 5$ retrata essa ação das MPEs.

Por exemplo, eu trabalho hoje com cinco bancos e estamos tentando o sexto banco e não estamos conseguindo entrar. Como está consolidado esse processo com esses bancos, eu utilizo de maneira natural a carteira de clientes para captação e estamos fechando com o sexto banco e uma carteira nova, é um caminho, ai depois a demanda vem naturalmente. A participação de mercado, ela acontece antes e vai acontecendo. Uma indicação do multiplicador pode demorar seis meses, até a pessoa entender e aceitar o trabalho. Não acreditamos em mala direta, não acreditamos em telemarketing. $O$ banco solicita $o$ valuation completo e trabalhamos com a carteira de clientes. (E5)

Por outro lado, o fator custo é convergente com achados teóricos. Ações como redução de preço para manter-se ou ampliar mercado são explicitadas pelos respondentes. A literatura trata esse assunto sugerindo que as MPEs devem agir conforme a ação dos concorrentes (CHEN, HAMBRICK, 1995), observando a dinâmica dos preços abaixo da competição (VEKATARAMAN, 1989), ou ainda quando ocorre reprodução por parte dos concorrentes, com preços abaixo dos praticados (DESS, LUMPKIN, 2005).

A presente pesquisa revela que a agressividade competitiva pode ser confundida com outras 
dimensões, tais como inovação e propensão ao risco, já que os respondentes das empresas ratificam principalmente a necessidade de desenvolver trabalhos com qualidade como forma de se manter no mercado. Essa situação é percebida quando o respondente da empresa E1 afirma que "há mercado para todo mundo", se valendo de observaçôes do ambiente. Por outro lado, o respondente da empresa E2 afirma que “...o cliente se vale muito daquilo que você faz, da qualidade de seu trabalho, na hora em que precisa você estar lá, acho que é por aî", reiterando as questóes sobre qualidade e comprometimento.

Por fim, observa-se que nos achados da presente pesquisa, assim como nos pressupostos teóricos, o cliente é o foco muito importante, com açóes que contribuem para estreitar relacionamentos, apresentar melhor qualidade de atendimento e aumentar participaçáo no próprio cliente em que já atua ou por meio de indicaçôes e ou networking.

\section{CONSIDERAÇÓES FINAIS}

Esta pesquisa teve por objetivo analisar se o comportamento de liderança do empreendedor de MPEs prestadoras de serviços contribui na disseminação das dimensôes da orientação empreendedora (OE) propostas por Lumpkin e Dess (1996). A OE é um campo de estudo do empreendedorismo; assim, suas dimensôes são fundamentais e complementares para tratar os aspectos relacionados à liderança no contexto das MPEs.

Ficou claro que, nesse ambiente de negócio, as açôes de liderança são, geralmente, direcionadas pelo próprio dono do negócio, refletindo no uso em maior ou menos extensão das dimensôes, ou ainda a criação de uma nova abordagem capaz de se adaptar para as empresas desse porte.

O estilo de liderança apregoado por Yukl, Gordon e Taber (2002) foi percebido nas empresas pesquisadas em níveis diferentes. Náo obstante ser observado o comportamento de tarefa nas empresas E1 e E5 e o comportamento de mudança na empresa E4, todas são, predominantemente, guiadas pelo comportamento do relacionamento interpessoal entre gestor-colaborador, por meio do reconhecimento das realizações, da autonomia dada aos colaboradores e do envolvimento deles nos processos de tomadas de decisóes.

Por outro lado, o estilo da liderança identificado traz consigo uma nova perspectiva quando associada com a OE. Embora a literatura focalize mais recorrentemente as dimensóes $\mathrm{da} \mathrm{OE}$ em empresas de grande porte, algumas dessas dimensôes são menos aderentes quando associadas à MPEs prestadoras de serviços.

Esses resultados propiciaram insights, como contribuição da presente pesquisa, de que algumas dessas dimensóes, como a autonomia, a efetividade, a interação e a propensão ao risco, precisam ser açóes praticadas nas MPEs, visando à sobrevivência, ganho de escala, competitividade e, ainda, comprometimento dos colaboradores para com a empresa. Ao associar essas reflexóes com a taxonomia de Yukl, Gordon e Taber (2002), abriram-se novas perspectivas, derivando um esquema integrativo que relaciona o estilo do líder com as dimensôes da $\mathrm{OE}$ para açôes no contexto de MPEs prestadoras de serviços (Figura 1). 


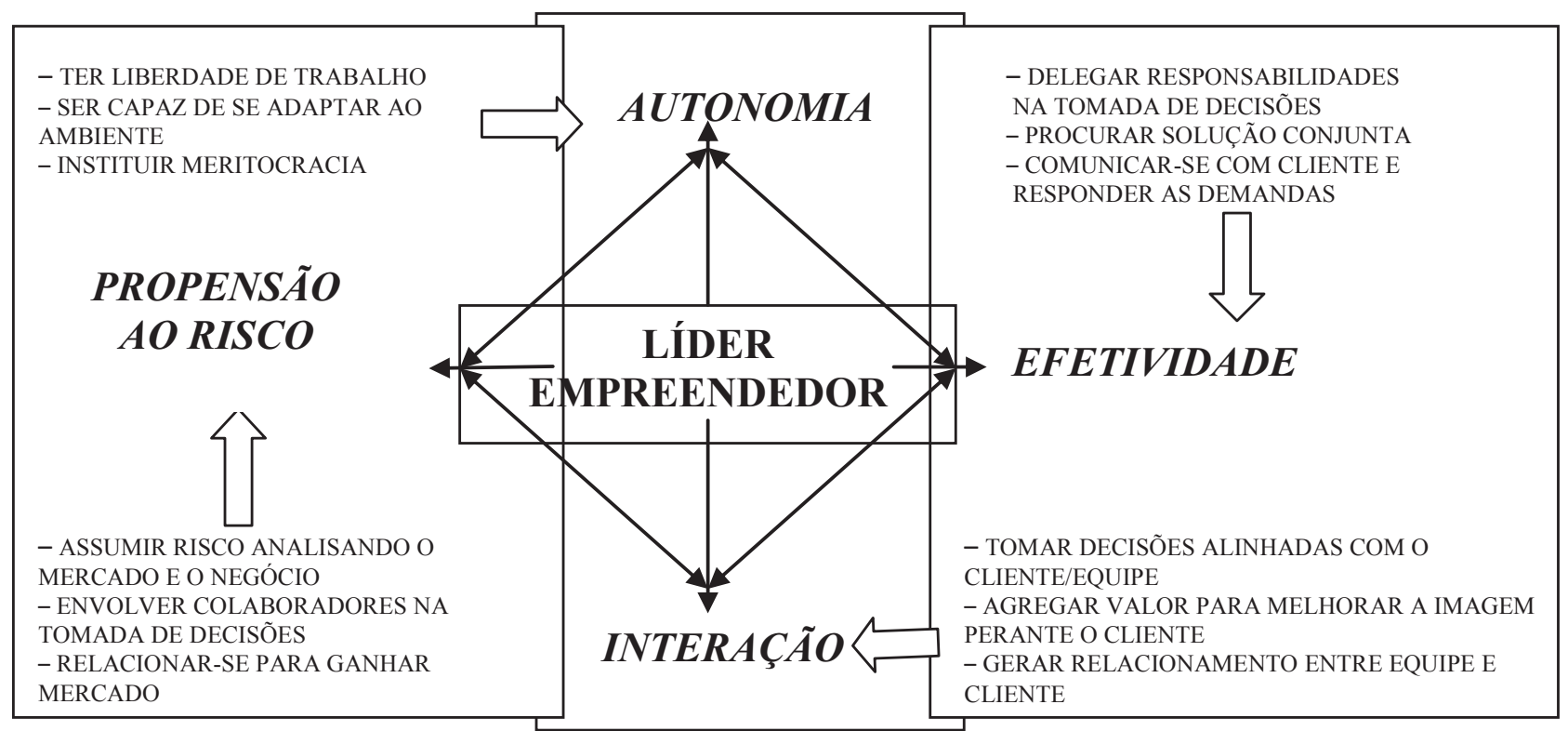

FIGURA 1 - Esquema integrativo das dimensóes da oe e os comportamentos de liderança do empreendedor

Fonte: Dos autores.

Esse esquema integrativo (Figura 1) possibilitou uma combinação as diversas açôes dos empreendedores, relacionando o estilo de liderança com as dimensôes da OE propostas para ambientes de MPEs prestadoras de serviços. O líder empreendedor se coloca no centro das açôes, exercitando suas atividades por meio das quatro dimensôes da OE. De forma geral, é possível identificar que, em relação às características de cada indivíduo, quanto mais o estilo de liderança se adapta para uma ou mais dimensão, sugere-se que os colaboradores podem se sentir mais incentivados a atuar da mesma forma. Assim, as dimensões da OE proposta para os empreendedores ficariam assim caracterizadas:

1. Empreendedor sob a dimensão autonomia: orienta a equipe para assumir responsabilidade e delega atividade, acredita no potencial dessa equipe e a treina para atingir o objetivo proposto. É participativo e está presente em todas as áreas da empresa.

2. Empreendedor sob a dimensão efetividade: orienta a equipe para atuar frente às situações adversas do cotidiano, que necessitam de resposta rápida e não somente em sua identificação. Dá poder de decisão e o colaborador age como tal na resolução de problemas.

3. Empreendedor sob a dimensão interação: orienta a equipe a estreitar relacionamento com clientes, realizar networking para captação de novos negócios e ser participativa no gerenciamento dos negócios.

4. Empreendedor sob a dimensão propensão ao risco: orienta a equipe para enxergar o mercado e as oportunidades, auxilia na tomada de decisão visando a ganho de parcela de mercado e captação de novas oportunidades através de relacionamentos com clientes já existentes e de outros potenciais.

Por outro lado, a pesquisa revelou que há dimensôes que possuem maior convergência entre elas, ou seja, há uma tendência de o líder empreendedor desenvolver ou possuir ao mesmo tempo duas ou mais dimensóes potenciais. Nesse sentido, com base na Figura 1, procurou-se projetar um possível perfil do colaborador desejado pelo líder. 


\begin{tabular}{|c|c|}
\hline Características do empreendedor & Características do colaborador \\
\hline Autonomia + Efetividade & $\begin{array}{l}\text { - Toma decisóes sem auxílio prévio. } \\
\text { - Analisa os elementos em conjunto para a melhor tomada de decisão. } \\
\text { - Assume a responsabilidade com o cliente e resolve o problema. }\end{array}$ \\
\hline Efetividade + Interação & $\begin{array}{l}\text { - É participativo nas decisóes da empresa. } \\
\text { - Busca melhorar imagem da empresa através de açóes bem sucedidas perante aos clientes. } \\
\text { - Envolve-se e torna-se referência no atendimento ao cliente. }\end{array}$ \\
\hline Interação + Propensão ao risco & $\begin{array}{l}\text { - Analisa as oportunidades de mercado e as apresenta na empresa. } \\
\text { - Auxilia na tomada de decisóes. } \\
\text { - Estreita o relacionamento para alavancar novos negócios e oportunidades. }\end{array}$ \\
\hline Propensão ao risco + Autonomia & $\begin{array}{l}\text { - É proativo. } \\
\text { - É receptível às mudanças, tornando-as uma oportunidade. } \\
\text { - Busca a melhoria contínua como forma de ser premiado. }\end{array}$ \\
\hline
\end{tabular}

QUADRO 9 - Alinhamento entre empreendedor-colaborador

Fonte: Dos autores.

O Quadro 9, ao buscar integrar a característica do empreendedor com as açóes desejadas de um colaborador, abre uma perspectiva relevante nessa importante relação empreendedor-colaborador para as MPEs prestadoras de serviços. Dessa forma, o empreendedor, ao identificar seu comportamento de liderança e ao adotar um critério para selecionar seus colaboradores, pode trazer consigo uma perspectiva de melhor aproveitamento dos recursos humanos e, consequentemente, melhor resultado para a empresa. Assim, abre-se uma possibilidade de futuras pesquisas.

Estudos enfatizam a importância de se manter nas organizações diferentes estilos de pessoas para suprir possíveis deficiências e, assim, terem comportamento complementares. Por outro lado, os resultados da presente pesquisa sugerem que para o contexto de MPEs prestadoras de serviços, a similaridade de açōes entre empreendedores e seus colaboradores são fatores importantes para que as empresas conquistem seus espaços no mercado competitivo e agressivo. Agir conjuntamente parece ser um dos principais alicerces de sobrevivência de MPEs no que tange à imagem perante o mercado e às açóes junto aos clientes, além da necessidade de serem proativos tanto na resolução de problemas quanto na busca por oportunidades e crescimento dentro do mercado já conquistado ou em potencial.

Este estudo não confirma os conceitos ora encontrados nas teorias que serviram de base para sua construção. Por outro lado, abre perspectivas para novas pesquisas, contribuindo com a ampliação de estudos e integrando a utilização das dimensôes OE com os comportamentos de lideranças do empreendedor.

Percebe-se ainda que, no cotidiano das açóes das empresas de MPEs, esse modelo de gestão pode auxiliar os empreendedores a buscar no mercado profissionais que possam agregar maior valor ao negócio, quando associado a seu estilo de gestão. Isso remete à necessidade de ampliar os estudos para a compreensão desse fenômeno. Ao que tudo indica, essas reflexóes podem abrir perspectivas para novos estudos nessa temática.

Por se tratar de uma pesquisa realizada com uma amostra restrita de empresas prestadoras de serviços, alocadas em uma determinada região, a ampliação do estudo é de grande importância. Sugere-se o aumento no número de empresas e abertura para outras regiôes, além de buscar por outros tipos de comportamentos de liderança de empreendedores, procurando identificar aderências junto às dimensões da $\mathrm{OE}$.

A importância de estudos dessa natureza pode contribuir com as MPEs no âmbito socioeconômico, bem como propiciar crescimento para se perpetuarem em um mercado altamente competitivo e instável. Por outro lado, há necessidade de o líder empreendedor alinhar seu estilo de liderança para agir de forma proativa e abrir caminhos autônomos e inovadores aos colaboradores, com o intuito de agregar valor aos negócios e ao ambiente e, como consequência, trazer maior retorno à empresa. 


\section{REFERÊNCIAS}

BARDIN, L. Análise de conteúdo. Lisboa: Ediçôes 70, 2008.

BESSANT, J.; TIDD, J. Inovação e empreendedorismo. São Paulo: Bookman, 2009.

BHIDÉ, A. The origine and evolution of new businesses. Oxford: Oxford University Press., 2004.

BOOTH, W. C.; COLOMB, G. G.; WILLIAMS, J. M. A arte da pesquisa. São Paulo: Martins Fontes, 2005.

BOUCHARD, V. Corporate entrepreneurship: lessons from the field, blind spots and beyond. European Entrepreneurial Learning: Cahiers de Recherche, [S.1.], n. 2002/08, Sept. 2002.

BURGELMAN, R. A. Strategy is destiny: how strategy-making shapes a company's future. New York: Free Press, 2001.

BURNS, J. M. Leadership. New York: Harper \& Row, 1978.

CHEMMERS, M. M.; FIEDLER F. E. Liderança e administraçáo eficaz. São Paulo: Pioneira, 1981.

CHEN, M. J.; HAMBRICK, D. C. Speed stealth and selective attack: how small firms differ from large firms in competitive behavior. The Academy of Management Journal, New York, v. 38, n. 32, p. 453-482, Apr. 1995.

COVIN, J. G.; LUMPKIN, G. T. Entrepreneurial orientation theory and research: reflections on a needed construct. Entrepreneurship: theory and practice, Malden, v. 35, n. 5. p. 855-872, Sept. 2011.

; MILES, M. P. Corporate entrepreneurship and the pursuit of competitive advantage. Entrepreneurship: theory and practice, Malden, v. 23, n. 3, p. 47-63, Spring 1999.

; SLEVIN, D. P. Strategic management of small firms in hostile and benign environments.
Strategic Management Journal, Chichester, v. 10, n. 1, p. 75-87, Jan./Feb. 1989.

DEGEN, R. J. O empreendedor: empreender como opção de carreira. São Paulo: Pearson Prentice Hall, 2009.

DESS, G. G.; LUMPKIN, G. T. The role of entrepreneurial orientation in stimulating effective corporate entrepreneurship. Academy of Management Perspective, [S.1.], v. 19, n. 1, p. 147-156, Feb. 2005.

GIBBS, G. Análise de dados qualitativos. Porto Alegre: Artmed, 2009.

GODOY, A. S. Refletindo sobre critérios de qualidade da pesquisa qualitativa. Gestáo.Org, Revista Eletrônica de Gestão Organizacional, Recife, v. 3, n. 2, p. 80-89, maio/ago. 2005. Disponível em: <http://www.revista.ufpe.br/ gestaoorg/index.php/gestao/article/view/136>. Acesso em: 13/03/2011.

JULIEN, P. A. Empreendedorismo regional e economia do conhecimento. São Paulo: Saraiva, 2010 .

KIRZNER, I. M. Competition and entrepreneurship. Chicago: Chicago University Press, 1973.

LEE, S. M.; PETERSON, S. J. Culture, entrepreneurial orientation and global competitiveness. Journal of World Business, Oxford, v. 35, n. 4, p. 401-416, Winter 2000.

LUMPKIN, G.; DESS, G. Clarifying the entrepreneurial orientation construct and linking it to performance. The Academy of Management Review, Briarcliff Manor, v. 21, n. 1, p. 135-173, Jan. 1996.

MACMILLAN, I. C.; DAY, D .L. Corporate ventures into industrial markets: dynamics of aggressive entry. Journal of Business Venturing, Amsterdan, v. 2, n. 1, p. 29-39, Winter 1987.

MARTENS, C. D. P. Proposiçáo de um conjunto consolidado de elementos para guiar 
açóes visando a orientação empreendedora em organizaçóes de software. 2009. 350 f. Tese (Doutorado em Administraçáo)-Universidade Federal do Rio Grande do Sul, Escola de Administração, Porto Alegre, 2009.

MARTINS, G. A.; THEÓPHILO, C. R. Metodologia da investigação científica para ciências sociais aplicadas. São Paulo: Atlas, 2009.

MERRIAM, S. B. Qualitative research and case study applications in education. San Francisco: Jossey-Bass Publishers, 1998.

MILLER, D. The correlates of entrepreneurship in three types of firms. Management Science, Linthicum, v. 29, n. 7, p. 770-791, July 1983.

; FRIESEN, P. H. Archetypes of strategy formulation Management Science, Linthicum, v. 24, n. 9, p. 921-933, May 1978.

Innovation in conservative and entrepreneurial firms: two models of strategic momentum. Strategic Management Journal, Chichester, v. 3, n. 1, p. 1-26, Jan./Mar. 1982.

MILLER, M; MILLER, I. B. Governance, social identity, and entrepreneurial orientation in closely held public companies. Entrepreneurship: theory and practice, Malden, v. 35, n. 5, p.1051-1076, Sept. 2011.

MORIN, E. M.; AUBÉ, C. Psicologia e gestáo. São Paulo: Atlas, 2009.

PERREN, L. Comparing entrepreneurship and leadership - a textual analysis. The Council for Excellence in Management and Leadership. Report from the SME working group, London: CEML. 2000.

REIS NETO, J. F. et al. As conexóes entre a orientação empreendedora, capacidade de marketing e a percepção do desempenho empresarial: evidencias empíricas das micro e pequenas empresas varejistas. RAM - Revista de Administração Mackenzie, São Paulo, v.13, n. 6, ed. especial, p. 236-271, maio/jun. 2013.

SALIM, C. S. Administraçáo empreendedora: teoria e prática usando estudos de casos. Rio de Janeiro: Campus, 2004.

SEBRAE. [2012]. Disponível em: <http://www. sebrae.com.br>. Acesso em: 15 jan. 2014.

SHANE, S.; VENKATARAMAN, S. The promise of entrepreneurship as a field of research. Academy of Management Review, Briarcliff Manor, v. 25, n. 1, p. 217-226, Jan. 2000.

SILVA, M. A. O. M.; GOMES, L. F. A. M.; CORREIA, M. F. Cultura e orientação empreendedora: uma pesquisa comparativa entre empreendedores em incubadoras no Brasil e em Porugal. RAC - Revista de Administração Contemporânea, Curitiba, v. 13, n. 1, p. 57-71, jan./mar. 2009.

VENKATARAMAN, N. Strategic orientation of business enterprises: the construct, dimensionality and measurement. Management Science, Linthicum, v. 35, n. 8, p. 942-962, Aug. 1989.

WIKLUND, J. The sustainability of the entrepreneurial orientation-performance relationship. Entrepreneurship: theory and practice, Malden, v. 24, n. 1, p. 37-48, Fall 1999.

YUKL, G. Leadership in organizations. 4. ed. London: Prentice-Hall International, 1998.

; GORDON, A.; TABER, T. A hierarchical taxonomy of leadership behavior: integrating a half century of behavior research. Journal of Leadership \& Organizational Studies, Thousand Oaks, v. 9, n. 1, p. 15-31, Summer 2002. 